\title{
Do recipients of cash transfer scheme make the right decisions on household food expenditure? A study from a rural district in Pakistan
}

Aminah Jahangir

Aga Khan University, aminah.jahangir@akdn.org

Shehla Zaidi

Aga Khan University, shehla.zaidi@aku.edu

Jai K. Das

Aga Khan University, jai.das@aku.edu

Shifa Habib

Community Health Solutions, Karachi, Pakistan

Follow this and additional works at: https://ecommons.aku.edu/pakistan_fhs_mc_chs_chs

Part of the Community Health and Preventive Medicine Commons, Food Security Commons, Food Studies Commons, Maternal and Child Health Commons, Nutrition Commons, and the Women's Health Commons

\section{Recommended Citation}

Jahangir, A., Zaidi, S., Das, J. K., Habib, S. (2020). Do recipients of cash transfer scheme make the right decisions on household food expenditure? A study from a rural district in Pakistan. JPMA. The Journal of the Pakistan Medical Association, 70(5), 796-802.

Available at: https://ecommons.aku.edu/pakistan_fhs_mc_chs_chs/707 


\title{
Do recipients of cash transfer scheme make the right decisions on household food expenditure? A study from a rural district in Pakistan
}

Aminah Jahangeer ${ }^{1}$, Shehla Zaidi², Jai Das³, Shifa Habib4

\begin{abstract}
Objective: To assess spending by beneficiaries of Benazir Income Support Programme on monthly food commodities, and contribution of the cash grant programme on purchase of nutritious foods. Methods: The descriptive cross-sectional survey of households enrolled in the Benazir Income Support Programme was conducted during July and August, 2013, in Matiari district of the Sindh province of Pakistan. Monthly household food expenditure on food commodities and use of the cash grant on type of food purchased was assessed through structured interviews of the beneficiaries. Results were computed in 2013 Pak rupees and converted to 2018 United States dollar. Women beneficiaries were also interviewed on decision-making regarding the use of the cash grant and on household food expenditure.
\end{abstract}

Results: The survey comprised 421 households. with a mean monthly expenditure on food of Rs 7,577, $r 80.73$ dollars. Women made decisions on food spending in only $135(32 \%)$ households, but in $235(56 \%)$ households, women were the primary decision-makers on cash grant spending. Conclusion: Unconditional cash grant did not meaningfully translate into the purchase of nutritious foods even though it played an important role in increasing women's agency. Keywords: Nutrition, Food expenditure, Food security, Cash transfer, Poor households.

(JPMA 70: 796; 2020). https://doi.org/10.5455/JPMA.16884

\section{Introduction}

Pakistan faces a high burden of under-nutrition, mainly affecting women and children, as $18 \%$ of adult women are thin or undernourished (body mass index [BMI] $<18.5$ $\left.\mathrm{kg} / \mathrm{m}^{2}\right), 44 \%$ of children $<5$ years are stunted, $32 \%$ are under-weight, $15 \%$ are wasted, ${ }^{1}$ and $25 \%$ of all children born report low birthweight (LBW). Micronutrient deficiencies are also endemic amongst women and children, as more than half of women and $<5$ children are anaemic with high prevalence of various micronutrient deficiencies, including iron, zinc, vitamin A and iodine. ${ }^{1}$

In Pakistan, around 58\% households are food-insecure, consuming less than, $2100 \mathrm{kcal}$ per person per day, ${ }^{2}$ with a rural and urban food insecurity at $60 \%$ and $52 \%$ respectively, and $9.8 \%$ of these food-insecure households have also reported severe hunger. Only $15 \%$ children aged $<2$ years have a minimum acceptable diet, and a mere

1 Aga Khan Foundation, Islamabad, Pakistan; 2 Department of Community Health Sciences, Aga Khan University, Karachi, Pakistan; ${ }^{3}$ Department of Women and Child Health, Aga Khan University, Karachi, Pakistan; ${ }^{4}$ Community Health Solutions, Karachi, Pakistan.

Correspondence:Shehla Zaidi. email: shehlasaz@gmail.com
$22 \%$ observe the minimum acceptable dietary diversity. ${ }^{1,3}$ Just over half (56.4\%) the children get their meals with an acceptable meal frequency. The consumption of food commodities with adequate micronutrient content and bioavailability, such as meat, vitamin A-rich fruits and vegetables, is suboptimal in children and women, with a frequency of $<0.4$ times per day. ${ }^{1}$ The major underlying determinants for dietary inadequacy and under-nutrition include poverty, lack of awareness, cash crop-based agriculture and lack of social protection for the poorest. ${ }^{4}$ Furthermore, owing to large average family size, $46 \%$ of the family income is spent on food while this figure is $35 \%$ for India. ${ }^{5}$

Cash transfers, conditional or unconditional, constitute an integral strategy for social protection in many developed and developing countries 6 and have been contributing to reduction of poverty gap and improvement in food security and consumption environment. Cash transfers have risen rapidly over the years in both emergency and developmental contexts and have had disparate reactions from various quarters. There are currently more than 130 low- and middle-income

Vol. 70, No. 5, May 2020 
countries (LMICs) with at least one non-contributory unconditional cash transfer programme, including poverty-targeted transfers and old-age social pensions. ${ }^{7}$ An evaluation of four government-run cash transfer programmes in sub-Saharan Africa --Ghana, Kenya, Lesotho and Zambia -- shows that programmes with regular and predictable transfer increase the quantity and quality of food, and reduce the prevalence of food insecurity, while transfers which are relatively smaller with irregular payments do not transform food expenditure. ${ }^{8}$

Pakistan has one of the biggest cash transfer programmes in the region known as Benazir Income Support programme (BISP). It is a large-scale unconditional cash transfer programme executed by the Government of Pakistan since 2008.9 It aims at reducing poverty by providing cash transfers to the poorest households without attaching any conditions to the actions of the recipients of the cash fund. Eligible households are identified through a poverty scorecard, and households with a monthly income of less than 6000 rupees (PKR) (United States dollar [US\$]57) and possession of durable assets less than the established benchmark, are eligible for cash grants. ${ }^{9}$ Increasing household food consumption and poverty reduction are the key intended impacts of the programme through a PKR 1000 monthly cash transfer at the programme outset which has since been increased to PKR 1500 per month. The scheme also intends to promote women empowerment by paying the cash stipend directly to women in eligible low-income families. The follow-up evaluation of BISP in 2015 concluded that BISP does not have an impact on overall food consumption expenditure even though $84 \%$ of the households reported expenditure from the BISP cash grant on food and nutrition. ${ }^{10}$ It also reported an increase in per-adult equivalent monthly food consumption (PKR 69) and increased independence of the beneficiary women. ${ }^{10}$ High rates of malnutrition were reported amongst children in BISP beneficiary households with $29 \%$ of boys and $25 \%$ of girls wasted in 2014.

BISP has the potential to add to gender-sensitive interventions onto agricultural, livelihood and food support schemes as a result of its extensive outreach and organised gender-based targeting.

The current study was planned to provide empirical evidence on the role of BISP cash transfers in improving dietary adequacy among low-income households in rural Pakistan.

\section{Subjects and Methods}

The descriptive cross-sectional survey of BISP-enrolled households was conducted in Matiari, Pakistan. The data was collected during July and August, 2013, while the study itself lasted a total of eight months. Matiari is a rural district in Sindh where under-nutrition levels are particularly high across the province, with $72 \%$ children $<5$ being anaemic, 53\% having vitamin A deficiency, $40 \%$ with iron deficiency and $60 \%$ of pregnant women being anaemic. ${ }^{1}$ Within Sindh, Matiari has one of the poorest health indicators in the province, with $51.6 \%$ children $<5$ underweight, $54.8 \%$ stunted, $16 \%$ wasted and an infant and $<5$ mortality rate of 81 and 101 per 1000 live births respectively. ${ }^{11}$ It is a largely agrarian district comprising large land-holdings and most of the populace works as tenant farmers, a pattern commonly found in Sindh. In Matiari, 85\% households are covered by BISP and were receiving a monthly cash stipend of PKR1000 at the time of data collection.

During the quantitative household survey, the primary outcomes of interest measured were total household expenditure on food and by various commodity groups (wheat/rice, fruits, vegetables, meat, oil/ghee, sugar, dairy and readymade food items); expenditure pattern of spending of cash grant on nutritious food; monthly food purchase pattern; and cashless and non-cashless sources of food. Secondary outcomes of interest measured were female beneficiaries' role in deciding cash grant expenditure; female beneficiaries participation in deciding household food expenditure; and household practice of who was served the meal first.

The survey was conducted using a close-ended structured questionnaire in Sindhi, the local language (Annexure A). The questionnaire, among other things, household demographic and socioeconomic status (SES) variables. Although all beneficiary households were officially listed as poor households, the SES was measured based on the asset index which was adapted from the household survey tool used for the Household Integrated Economic Survey (HIES) ${ }^{12}$ periodically conducted under the Pakistan Social and Living Standards Measurement Survey (PSLM). ${ }^{13}$ The asset index was devised by computing average selling prices of the assets, including land, cattle, vehicles and other household commodities. These were then divided into first, second and third SES terciles with the first tercile representing the better-resourced and the third tercile representing the lower-resourced households among the 


\section{BISP beneficiaries.}

After obtaining approval from the ethics review committee of Aga Khan University (AKU), Karachi, Tthe sample size was calculated using average household expenditure on food for rural Sindh reported in HIES 12 based on the range of 20 and 80 percentile of the household expenditure on food. An assumption of standard deviation of PKR 1277, a bound of error PKR 150 and 5\% level of significance were applied. The sample size was further increased to allow for multi-stage sampling with a design effect of 1.5 and a non-response rate of $10 \%$.

In the first stage, five villages, from each of the five union councils, the smallest administrative unit, of Taluka Matiari were selected randomly and in the next stage, 17 households from each village were randomly selected as secondary sampling units. A household was identified eligible for inclusion in the study if at least one female aged 15-49 years was enrolled with BISP and had at least one child of $<5$ years. Informed written consent was obtained from the respondents before inclusion in the study (Annexure B). All questionnaires were coded with a number for confidentiality of information during analysis. If any selected household had more than one beneficiary, only one was randomly selected.

The research team trained four data collectors and the tool was pre-tested on $10 \%$ of the total required households for adjustment prior to actual data collection. Data collectors were supervised during the data collection process and random visits were made to directly observe the process of interviewing by data collectors in the field. All the filled questionnaires were reviewed for completeness and eligibility, and de-identified data was used for data entry through a programme developed on
Visual Fox. After double data entry, both data sets were compared for completeness and data entry errors. In case of errors, respective questionnaires were referred to make corrections and data was cleaned. Finally, investigators assessed $10 \%$ of total sample size forms for errors to ensure correct data entry. Data was analysed using SPSS 19. Mean with standard deviation (SD) were calculated for descriptive variables. One-way analysis of variance (ANOVA) was used to compare the differences in means of household food expenditure by SES terciles. Cost data was collected and reported in terms of PKR in 2013 terms. Results were converted to US\$2013 based on exchange rate for 2013 and then converted to US\$2018 by adjusting for dollar inflation based on the consumer price index (CPI).

\section{Results}

Of the 421 households surveyed, 356(86\%) had been enrolled in the BISP for more than a year. The mean household size 8 (ID 1.9); 278(65\%) household heads were employed in agriculture; $101(24 \%)$ in public or private jobs; 46(11\%) were unemployed; $25(6 \%)$ households owned agricultural land; 363(86\%) female beneficiaries were aged $<40$ years; and 391(93\%) were illiterate. The mean monthly expenditure on food was PKR 7,577 \pm 3044 , translating into US\$74.5 at 2013 PKR-US\$ exchange rate of 101.7. Applying a CPI inflation increase of $8.36 \%$ from 2013 to 2018 , the amount became equivalent of US\$80.7 in 2018 terms.

Highest monthly food expenditure was reported by the first SES tercile with a mean of PKR 8,844 \pm 3815 while the third SES tercile reported the lowest food expenditure PKR 6,502 $\pm 2032(p<0.001)$.

Maximum food spending was on wheat/rice followed by milk/dairy products, edible oil/ghee, sugar and tea, and

Table-1: Monthly Household Expenditure by Food Commodities and breakdown by socio-economic status (SES) Terciles (in Pak Rupee) (n-421).

\begin{tabular}{|c|c|c|c|c|c|}
\hline Expenditure Pattern & $\begin{array}{c}\text { Overall } \\
\text { Mean } \pm S D\end{array}$ & $\begin{array}{r}\text { 1stTercile } \\
\text { Mean } \pm \text { SD }\end{array}$ & $\begin{array}{l}\text { 2nd Tercile } \\
\text { Mean } \pm S D\end{array}$ & $\begin{array}{l}\text { 3rd Tercile } \\
\text { Mean } \pm S D\end{array}$ & $p$-value \\
\hline Total Monthly Food Expenditure & $7577 \pm 3044$ & $8844 \pm 3815$ & $7402 \pm 2450$ & $6502 \pm 92032$ & $<0.001$ \\
\hline Wheat/ rice & $2755 \pm 1581$ & 33.9 & 36.5 & 39.4 & 0.52 \\
\hline Milk/dairy products & $1125 \pm 1083$ & 14.4 & 15.2 & 15 & 0.078 \\
\hline Edible 0il/Ghee & $1005 \pm 608$ & 13.8 & 13.6 & 12.8 & 0.001 \\
\hline Sugar & $762 \pm 444$ & 10.3 & 9.6 & 10 & 0.001 \\
\hline Tea & $520 \pm 298$ & 6.8 & 7.2 & 7.4 & 0.001 \\
\hline Vegetables & $499 \pm 295$ & 6 & 6.5 & 6.8 & 0.001 \\
\hline Pulses & $356 \pm 203$ & 4.6 & 5.1 & 4.5 & 0.001 \\
\hline Meat & $310 \pm 415$ & 5.4 & 3.7 & 2 & 0.001 \\
\hline Prepared food products & $138 \pm 88$ & 2.3 & 1.6 & 1.1 & 0.001 \\
\hline Fruits & $103 \pm 198$ & 2.2 & 1 & 0.5 & 0.001 \\
\hline
\end{tabular}

SD: Standard deviation

Vol. 70, No. 5, May 2020 
Table-2: Expenditure on Food Commodities using household (HH) Income and Cash Grant (in Pak Rupee) ( $\mathrm{n}=421$ ).

\begin{tabular}{lcccc}
\hline Food Commodities & $\begin{array}{c}\text { Absolute amount from monthly } \\
\text { HH income all sources: Mean } \mathbf{S D}\end{array}$ & $\begin{array}{c}\text { \% Breakdown of HH income } \\
\text { spending by food item }\end{array}$ & $\begin{array}{c}\text { Absolute amount from } \\
\text { monthly cash grant: Mean } \pm \text { SD }\end{array}$ & $\begin{array}{c}\text { \% Breakdown of cash grant } \\
\text { spending by food item }\end{array}$ \\
\hline Total monthly food expense & $7,577 \pm$ SD 3044 & & $668 \pm$ SD266) & \\
Wheat/rice & $2755 \pm 1581$ & 36 & $147 \pm 204$ & 22 \\
Milk & $1125 \pm 1083$ & 15 & $69 \pm 111$ & 10 \\
Edible 0il & $1005 \pm 608$ & 13 & $14 \pm 46$ & 2 \\
Sugar & $762 \pm 444$ & 10 & $51 \pm 97$ & 8 \\
Tea & $520 \pm 298$ & 7 & $35 \pm 68$ & 5 \\
Vegetables & $499 \pm 295$ & 7 & $12 \pm 43$ & 2 \\
Pulses & $356 \pm 203$ & 5 & $11 \pm 27$ & 2 \\
Meat & $310 \pm 415$ & 4 & $123 \pm 152$ & 18 \\
Packet foods & $138 \pm 88$ & 2 & $112 \pm 208$ & 17 \\
Fruits & $103 \pm 198$ & 1 & $22 \pm 60$ & 3 \\
Others (prepared food) & & & $73 \pm 66$ & 11
\end{tabular}

SD: Standard deviation

Table-3: Cash Grant Food Purchases: Breakdown by One time versus Daily Purchase $(n=421)$.

\begin{tabular}{lcc}
\hline Food Commodity Type & \multicolumn{2}{c}{ Purchasing Pattern } \\
& $\begin{array}{c}\text { Proportion spent on } \\
\text { One-time Purchase }\end{array}$ & $\begin{array}{c}\text { Proportion spent on } \\
\text { Daily Purchase }\end{array}$ \\
\hline Wheat/Sugar/Tea & $60 \%$ & $40 \%$ \\
Meat/Chicken & $85 \%$ & $15 \%$ \\
Packed Food Items & $90 \%$ & $10 \%$ \\
Milk/Dairy Products & $80 \%$ & $20 \%$ \\
Vegetables & $100 \%$ & $0 \%$ \\
Fruits & $80 \%$ & $20 \%$
\end{tabular}

only wheat and milk spending did not show variation across the SES terciles, while all other commodities show decreased spending in the lowest SES group when compared to the highest SES group (Table 1). A comparison across SES terciles showed that meat, vegetables and fruit spending decreased across SES groups as it was significantly lower in SES group $3(p=0.001)$. The most frequent reported use of the BISP cash grant was on food purchase reported by 379(90\%) households, followed by spending on healthcare $227(54 \%)$, clothing 210 (50\%) and debt payment 51(12\%) households. A mean of PKR 669 \pm 266.4 from the cash grant was spent on food which amounted to $68 \%$ of the monthly cash grant of PKR1000, and 9\% of the total monthly mean household food expenditure of PKR 7577 \pm 3044 . From the amount spent on food, mean spending on packet foods, like crisps, biscuits etc., was PKR112 \pm 208 , and that on prepared foods, like biryani etc., was PKR 73 \pm 66 ). Of the remaining amount, expenditure was on routine monthly household food items PKR $123 \pm 152$ on meat and PKR 147 \pm 204 ) on wheat purchase, amounting to $22 \%$ and $18 \%$ of the cash grant (Table 2).

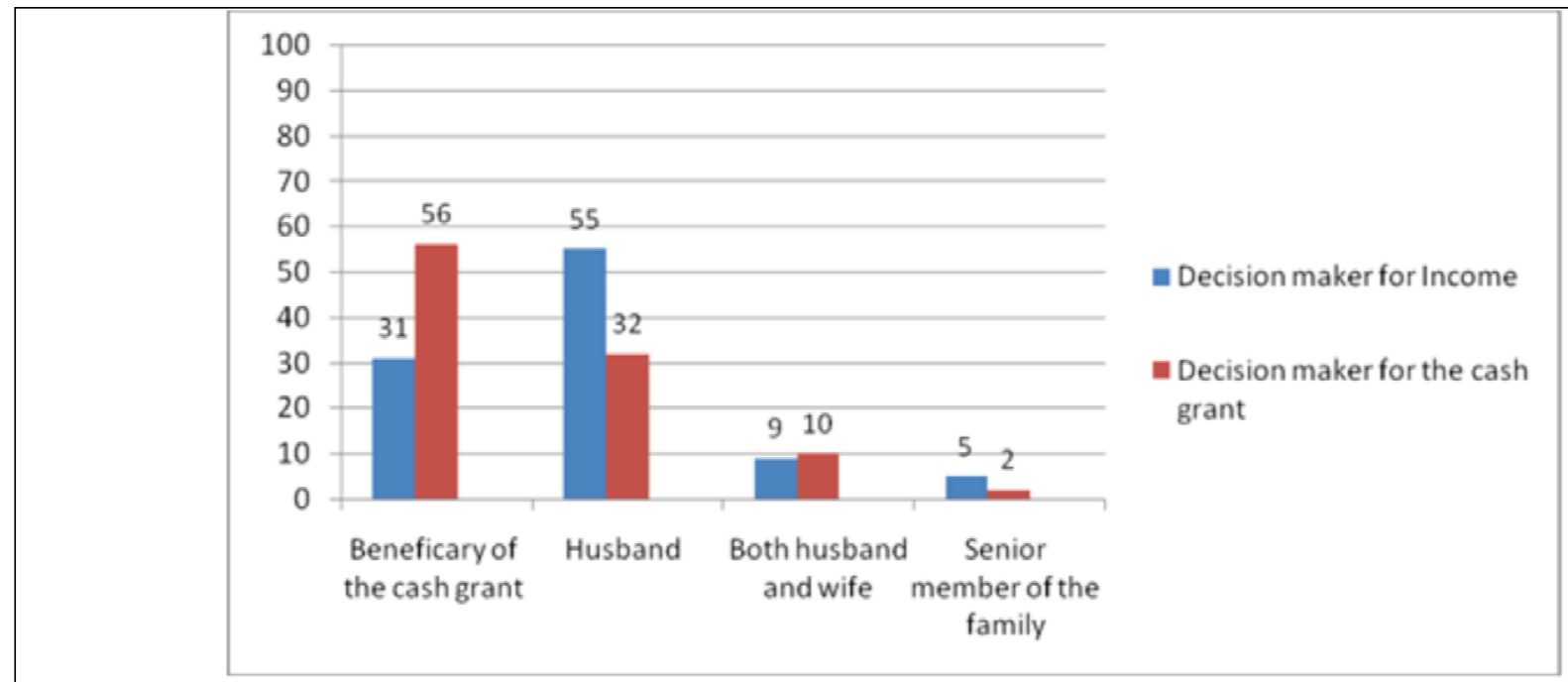

Figure: Decision-maker for spending cash grant versus decision-maker for spending household monthly income: \% of responses $(n=421)$. 
The results show that the cash grant was mainly used for one-time purchase for all food categories and a lesser amount was spared for daily purchases, and meat spending was mostly a one-time purchase rather than a steady source of meat throughout the month (Table 3). Of all the respondents, 379(97\%) reported that food was easily available in the local market. Households mainly relied on cash purchase of food and few households had supplementary cashless resources. Cashless source of wheat was available to only $43(10.2 \%)$ households that produced wheat on self-owned lands and belonged to the higher SES brackets. Households in the lower two SES brackets received wheat as in-kind payment for their labour. Similarly, only 68(16.2\%) households obtained dairy products from self-owned livestock. No household reported cashless sources of meat, fruits and vegetables.

Decision on overall monthly food spending was taken by males in 231(55\%) households, and by females in $130(31 \%)$. In the case of cash grant spending, proportionately more females had control over how it was to be spent (Figure). Female beneficiaries alone took decision on expenditure of cash grant in 235(56\%) households, while males alone took decision in 135(32\%) households, and both husband and wife collectively took decision in 42(10\%) households. In 193(45.8\%) households, men were served meals first, while in $126(30 \%)$ households all family members consumed their meals together, and in $93(22 \%)$ households, children were served first.

\section{Discussion}

Findings showed that BISP beneficiary households were mainly reliant on cash for purchasing food and, hence, cash grants were an important source of supplementary income for food purchases. Mean monthly household expenditure on food was PKR 7,577 (US\$80.7). The higher SES groups among the BISP beneficiaries had significantly higher household food expenditure, but food expenditure across all SES terciles was mainly on energy-dense food items (wheat / oil etc.) rather than on nutrient-rich food (vegetables, fruits and meat). The BISP cash grant was frequently use to aid the spending on food, but did not improve the spending on nutrient foods. The cash grant was frequently spent on one-time and random purchases of energy-dense foods rather than a steady supply of nutrient-rich goods. The energy-dense foods have a large number of calories per serving. Energy density is the amount of energy, as represented by the number of calories, in a specific weight of food and is determined by the proportion of macronutrients (protein, fat, carbohydrates). An example of a food with high energy density is the one which has many calories from sugar, wheat or rice and fat that fit a small serving size. The relationship of cash transfers and food spending has not been the subject of in-depth research in Pakistan. A national BISP assessment has reported on how frequently the cash grant was spent on food ${ }^{13}$ whereas we further examined the type of food commodities it was spent on. Our findings are similar to a study from Brazil which also reported that unconditional cash transfers were associated with higher spending on food products lacking any nutritional value. ${ }^{14}$ Income supplementation through unconditional cash transfers alone has been found to be insufficient for improving diets unless complementary interventions that increase the awareness on dietary diversity are integrated within the programme.13 Cash transfers, when linked with conditionalities such as nutrition education for mothers and child growth monitoring, have shown to have a positive impact on maternal and child nutrition and growth outcomes. ${ }^{15,16}$ Conditional cash transfer (CCT) programmes have become increasingly popular, as an alternative to traditional social assistance programmes. ${ }^{17}$ Evidence from 'Familias en Acción' programme in Colombo, 'Red de Protecció Red de Protección Social' programme in Nicaragua and PROGRESA programme in Mexico demonstrated an increase in the household expenditure on food, and in Mexico and Brazil, CCT programmes have been integral in improving the quantity and quality of food consumption and, in turn, reduction of under-nutrition.18-21 Supplementary interventions in addition to cash transfers have been practised in humanitarian settings. An evaluation of Ethiopia's Productive Safety Net Programme suggests that food transfers or 'cash plus food' packages are superior to cash transfers alone. ${ }^{22}$

Deep-rooted patriarchy in the South Asian communities is well noted as an underlying contributor towards poor health outcomes for females, such as poor pregnancy outcomes, malnutrition, anaemia and growth deficiencies. Our findings showed that in majority of the participating BISP households, men were given preferences for meals serving, further diluting any potential nutritional advantage of the cash grant for women and children. In none of the households, females were given preference for meals irrespective of their pregnancy and lactation 
status, which was consistent with the existing literature for intra-household food distribution in rural settings of Pakistan.23 The study, however, serves to show that the BISP cash grants helped increase women's agency in terms of decision-making by women on what to purchase as proportionately more female recipients were found to be exercising choice on food purchases through the cash grant compared to the proportion of women involved with decisions of general household food expenditure. A multi-country evaluation of women decision-making in cash and food transfer programmes in Ecuador, Yemen and Uganda highlighted large variations in decisionmaking ranking of women. ${ }^{24}$ Other studies have suggested that women empowerment through cash transfers manifested in terms of reduction in intimate partner violence. 25

Predominant reliance on cash for food purchase, as seen in the study context, has important implications for food insecurity. Our findings showing extremely low reliance on cashless food resources are consistent with the HIES 2012 that reported Sindh as having the highest percentage of agricultural landless households.12,26 Tenant farmers having little access to food grown on land are mainly reliant on food purchase through cash, which makes lowincome households very vulnerable to food price hikes. This flags the need for food security interventions for small or landless farmers for expanding reliance on cashless food sources such as through support of livestock and small farming enterprises.

The study has its limitations. First, the study design was cross-sectional and only measured spending at one point in time rather than over a time period. Second, it did not allow comparison of household expenditure pattern before the BISP was rolled out. Third, the study focussed on household food purchases rather than food consumption. Hence, it did not seek specific data on what mothers and children actually consumed, and assumed that food purchases were equitably distributed across all household members. Future research is needed to adequately probe the dynamics of food consumption in the household as an important but under-looked variable for improving nutritious diet. Lastly, the study data relates to 2013-14 which is a bit dated. However, since the policy landscape regarding cash transfers and food insecurity has remained largely unchanged, the findings still provide a relevant argument for link between BISP and nutrition.

\section{Conclusion}

Household food expenditure by BISP beneficiaries was mostly on energy-dense food, and the provision of unconditional cash transfers did not translate into increased spending on nutrient-rich food. The cash transfers, however, increased women's decision-making on the extent of cash grant spending on food and choice of food purchases. Effective translation of the potential of cash grant for purchase of nutritious foods needs support of nutrition awareness on appropriate food purchases, potential introduction of conditionalities for type of purchase as well as increasing cashless food resources to improve dietary diversity.

Acknowledgement: We are grateful to Iqbal Azam, Romaina Iqbal and Sajid Soofi for their input regarding the study proposal and data collection.

Disclaimer: None.

Conflict of Interest: None.

Source of Funding: None.

\section{References}

1. NNS 2011: National Nutrition Survey Pakistan, 2011. Aga Khan University, Pakistan Medical Research Council, UNICEF, Nutrition Wing Cabinet Division, Government of Pakistan, Islamabad; 2011.

2. World Food Programme (WFP). Pakistan Food Security Bulletin. December 2014, Issue 2. [Online] [Cited 2016 April 10]. Available from: URL: http://documents.wfp.org/stellent/groups/ public/documents/ena/wfp271228.pdf.

3. Haddad L, Achadi E, Bendech MA, Ahuja A, Bhatia K, Bhutta ZA, et al. The Global Nutrition Report 2014: Actions and Accountability to Accelerate the World's Progress on Nutrition. J Nutr $2015 ; 145$ : 663-71.

4. Zaidi S, Mohmand SK, Hayat N, Acosta AM, Bhutta ZA. Nutrition Policy in the Post devolution Context in Pakistan: An Analysis of Provincial Opportunities and Barriers. IDS Bulletin 2013; 44: 86-93

5. Washington State University. Annual income spent on food. Washington state magazine. 2008. [Online] [Cited 2016 June 15]. Available from: URL: http://wsm.wsu.edu/researcher/ WSMaug11_billions.pdf

6. Schubert B, Slater R. Social Cash Transfers in Low Income African Countries: Conditional or Unconditional? Development Policy Review 2006; 24: 571-8.

7. Honorati M, Gentilini U, Yemtsov RG. The state of social safety nets 2015. World Bank Group, Washington DC. [Online] [Cited 2016 June 15]. Available from: URL: http://documents.worldbank.org/curated/ en/2015/07/24741765/state-social-safety-nets-2015.

8. Tiwari S, Daidone S, Ruvalcaba MA, Prifti E, Handa S, Davis B, et al. Impact of cash transfer programs on food security and nutrition in sub-Saharan Africa: A cross-country analysis. Global Food Security 2016; 11: 72-83.

9. Cheema I, Farhat M, Hunt S, Javeed S, Pellerano L, Leary S. First Impact Evaluation of Benazir Income Support Programme. Oxford Policy Management Group, 2014. [Online] [Cited 2016 June 15]. Available from: http://bisp.gov.pk/wp-content/uploads/ 2016/10/BISPFirstImpactEvaluationReport.pdf.

10. Cheema, I, Farhat, M, Hunt, S Javeed S, Keck K, Leary S. Second 
Impact Evaluation of Benazir Income Support Programme: Report. Oxford Policy Management 2015. [Online] [Cited 2016 July 15]. Available from: URL: http://bisp.gov.pk/wp content/uploads/2016/10/2ndImpactEvaluation.pdf.

11. MICS 2014. Multiple Indicator Cluster Survey Sindh Final Report 2014. Karachi, Pakistan: Sindh Bureau of Statistics and UNICEF; 2014.

12. HIES 2013. Household Integrated Economic Survey 2011-12. Pakistan Bureau of Statistics, Government of Pakistan, Islamabad. May 2013. [Online] [Cited 2017 Oct 25]. Available from: URL http://www.pbs.gov.pk/sites/default/files/pslm/publications/hie s11_12/Complete_report.pdf

13. PSLM. Pakistan Social and Living Standards Measurement Survey (round - viii) district level 2012-13. Pakistan Bureau of Statistics, Government of Pakistan, Islamabad questionnaire. [Online] [Cited 2017 Nov 17]. Available from: URL: http://www.pbs.gov.pk/sites/ default/files//pslm/publications/District\%20QUESTIONNAIRE\%2 02012-13\%28ENG\%29_.pdf.

14. Lignani J, Sichieri R, Burlandy L, Salles-Costa R. Changes in food consumption among the Programa Bolsa Familia participant families in Brazil. Public Health Nutr 2011; 14: 785-92.

15. Guyon $A B$, Quinn VJ, Hainsworth $M$, Ravonimanantsoa P, Ravelojoana V, Rambeloson Z, et al. Implementing an integrated nutrition package at large scale in Madagascar: the Essential Nutrition Actions framework. Food Nutr Bull 2009; 30: 233-44.

16. Rosato M, Laverack G, Grabman LH, Tripathy P, Nair N, Mwansambo $C$, et al. Community participation: lessons for maternal, newborn, and child health. Lancet 2008; 372: 962-71.

17. Guldan GS, Fan HC, Ma X, Ni ZZ, Xiang X, Tang MZ. Culturally appropriate nutrition education improves infant feeding and growth in rural Sichuan, China. J Nutr 2000; 130: 1204-11.

18. Aguero M, Carter R, Woolard I. The impact of unconditional cash transfers on nutrition: The South African Child Support Grant. Working Papers 39, International Policy Centre for Inclusive Growth,
Brazil: 2006.

19. Maluccio J, Flores R. Impact evaluation of a conditional cash transfer program: The Nicaraguan Red de Protección Social. Discussion Paper No.184. International Food Policy Research Institute, Washington DC; 2005.

20. Ningenda G, Gonzáles-Robledo LM. Lessons offered by Latin American cash transfer programmes, Mexico's Opportunidades and Nicaragua's SPN: Implications for African countries Published by DFID; 2005.

21. Hoddinott, J. Nutrition and conditional cash transfer programs in Latin America: A magic bullet to reduce poverty, eds. M. Affidato and J. Hoddinott. Washington, DC: International Food Policy Research Institute (IFPRI); 2008.

22. Attanasio O, Gomez LC, Heredia P, Vera-Hernandez M. The ShortTerm Impact of a Conditional Cash Subsidy on Child Health and Nutrition in Colombia. Centre for the Evaluation of Development Policies, Institute of Fiscal Studies; 2005.

23. Sabates-Wheeler R, Devereux S. Cash transfers and high food prices: Explaining outcomes on Ethiopia's Productive Safety Net Programme. Food Policy 2010; 35: 274-85.

24. Holmes J. Do community factors have a differential impact on the health outcomes of boys and girls? Evidence from rural Pakistan. Health Policy Planning 2006; 21: 231-40.

25. Peterman A. Measuring Women's Decision Making: Indicator Choice and Survey Design Experiments from Cash and Food Transfer Evaluations in Ecuador, Uganda, and Yemen. Discussion Paper 1453, International Food Policy Research Institute, 2015. [Online] [Cited 2017 Dec 8]. Available from: URL: https://papers.ssrn.com/ sol3/papers.cfm? abstract_id=2685232.

26. Hidrobo $M$, Peterman $A$, Heise $L$. The effect of cash, vouchers, and food transfers on intimate partner violence: evidence from randomized experiment in Northern Ecuador. Am Economic J Applied Economics 2016; 8: 284-303. 